\title{
Prevalence of discomfort/pain complaints and related factors in dental professionals of the public health service in Araucária, Paraná state, Brazil
}

\author{
Rosimeire Sedrez Bitencourt ${ }^{\mathrm{a}}$ and Maria Isabel Ricardo ${ }^{\mathrm{b},{ }^{*}}$ \\ ${ }^{\text {a }}$ Federal University of Rio Grande do Sul, Brazil \\ ${ }^{\mathrm{b}}$ Federal University of Paraná, Brazil
}

\begin{abstract}
This poster presents a study about the influence of gender related factors, age, body weight, time of service in the profession and practice of physical exercise on the prevalence of discomfort/pain complaints in dental professionals. The scope of this study was limited to 123 subjects, $84.24 \%$ of professionals in the public dental clinics, who answered the multidimensional analytical work questionnaire. The data suggest that the lack postural awareness can contribute to the maintenance of painful conditions and also the low commitment to self-care can perpetuate the state of musculoskeletal discomfort/pain, justifying the application of the ergonomics concepts in the workplace and systematic guidance to professionals to adopt a healthy lifestyle.
\end{abstract}

Keywords: ergonomics; musculoskeletal pain; postural awareness

\section{Introduction}

In general, the dentists are subjected to overloads physical and often inadequate postures. Authors like [1-2] investigated the prevalence of musculoskeletal complaints in dentists and report high prevalence rates, which vary between 50 and $90 \%$ in the populations studied, indicating that some risk factors could be associated to musculoskeletal disorders, such as gender, age, work position, work hours and stress.

Musculoskeletal discomfort in different body regions have been the focus of numerous studies, however this poster presents a study that sought to identify and evaluate the influence of gender related factors, age, body weight, time of service in the profession and practice of physical exercise on the prevalence of discomfort/pain complaints in dental professionals and verify the awareness about postures adopted at work and prevailing attitudes of selfcare in relation to these complaints.

\section{Method}

The scope of this study was limited to one hundred twenty-three subjects, $84.24 \%$ of professionals in the public dental clinics, who answered the multidimensional analytical work questionnaire [5].

\section{Results}

The characterization of discomfort/pain complaints in one or more body regions was one hundred and eighteen $(95.9 \%)$ cases, with prevalence in the shoulder region in females. In both genders the right side

* Ricardo. Maria Isabel. E-mail: mariairicardo@hotmail.com. 
of cervical, lumbar and dorsal spine together with left shoulder was the most affected.

Factors associated with gender and age had little or no interference on the discomfort/pain prevalence, regarding to body mass index (BMI) and time of service has identified a correlation between those variables. Was evidenced a low perception of various movements in dental practice, figure 1.

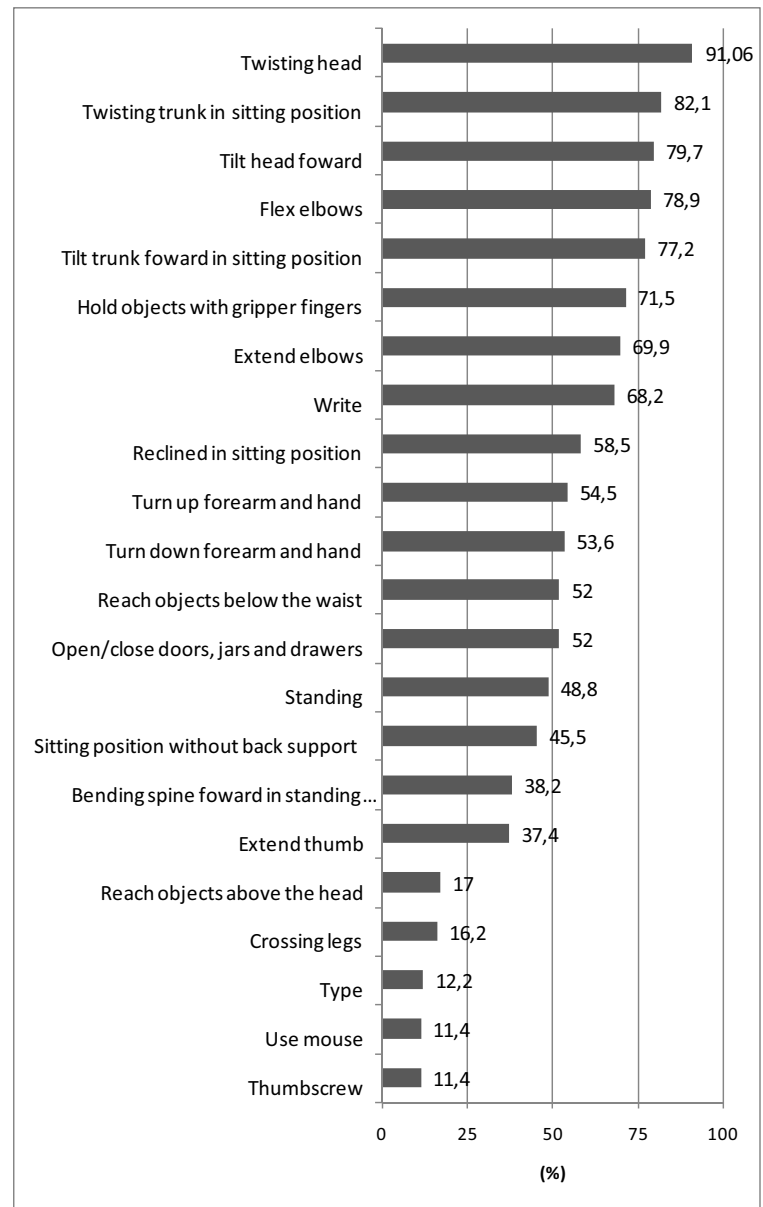

Fig. 1 Perception representation of often adopted postures at work.

Overall, the perception of most adopted postures in work routine was lower than expected, none of them were marked by $100 \%$ of professionals that develop such postural attitudes. It drew attention, particularly, the low perception of upper limbs and hands movements. The movement of reach objects above the head is routine to dental surgeons, being used to achieve the reflector, only 21 of 46 signaled the movement.

Author[4] reports that many times, without realizing it, to a task implement in certain workplace, man generates mechanical overload in musculoskeletal structures, especially when adopt inappropriate occupational or functional postures due to poorly designed workstations.

Figure 2 shows a comparison between categories in relation to discomfort / pain complaints. In this study, $06(4.07 \%)$ professionals did not report any musculoskeletal complaints, 117 (95.93\%) informed some level of discomfort / pain.

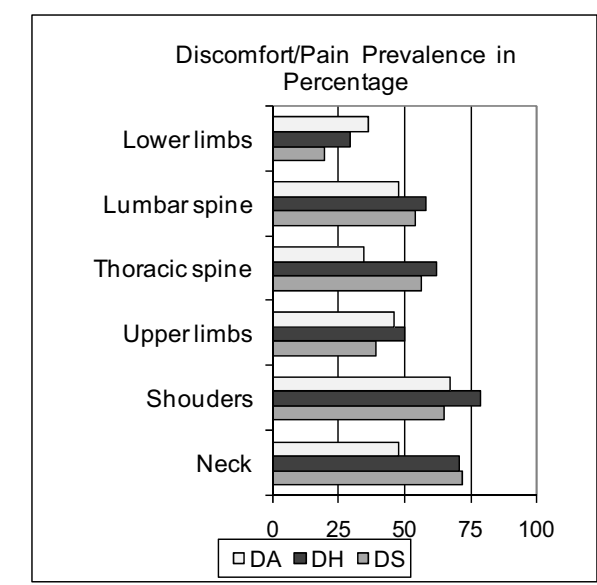

Fig. 2 Comparative of discomfort/pain prevalence between categories.

Dental assistants presented the lowest attitudes indication about discomfort/pain. Stretching was one of the most marked attitudes by professionals as discomfort/pain relief mechanism (Figure 3). As you move or stretch required muscles in task, there is an increase in local blood flow, with removal of accumulate metabolities that promote nerve and muscle fibers irritative mechanism, leading to discomfort relief and muscle contraction capacity recovery [3].

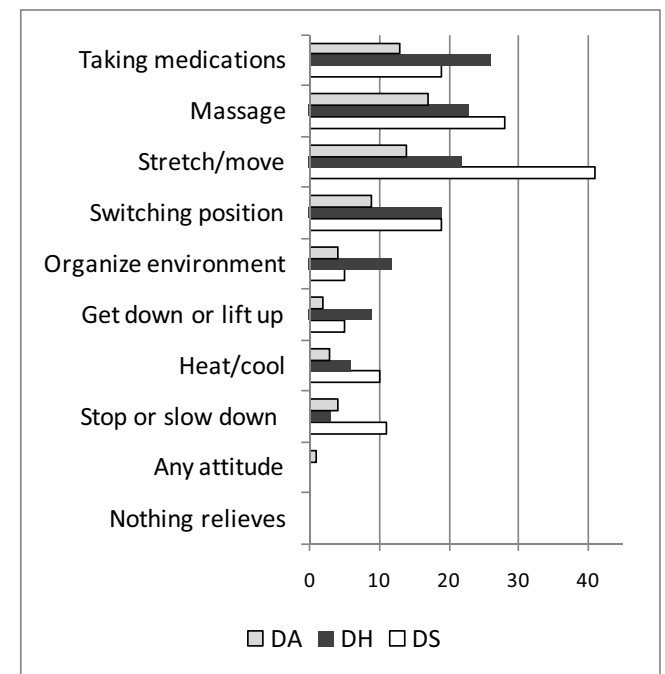

Fig. 3 Comparative between categories about adopted attitudes in relation to discomfort/pain. 


\section{Discussion}

The data suggest that the lack postural awareness can contribute to the maintenance of painful conditions and also the low commitment to self-care can perpetuate the state of musculoskeletal discomfort/pain, justifying the application of the ergonomics concepts in the workplace and systematic guidance to professionals to adopt a healthy lifestyle.

\section{References}

[1] Alexandre Crespo Coelho da Silva Pinto, Gymnastics applied to the health of dental surgeons - a case study in municipal health department of the City of Florianopolis - SC, Brazil. 137 f. Dissertation (in Ergonomics) - Graduate Program in Production Engineering, UFSC, Florianópolis - SC. 2003.
[2] Avrun.Kotliarenko et al., Musculoskeletal disorders and associated factors in dental surgeons from the western state of Santa Catarina, Brazil. Rev. Odontologia e ciências; 24(2):173179. 2009.

[3] Gisela Rocha Siqueira et. al., Evaluation of work-related musculoskeletal disorders of the employees FADE-UFPE. Rev. Reabilitar, São Paulo, Brazil. Editora Pancast, Year 8, No 30, p. 27-33, first quarter. 2006

[4] Joseph. Knoplich, Disease of the spine. Rio de Janeiro -RJ, Brazil. Ed. Pan, 1986.

[5] M. I. Ricardo, Prevalence of discomfort/pain complaints and related factors in dental professionals of the public health service in Araucária, PR. Specialization in ergonomics. Department of Physical Education Federal University of Paraná, Brazil. 2011 